
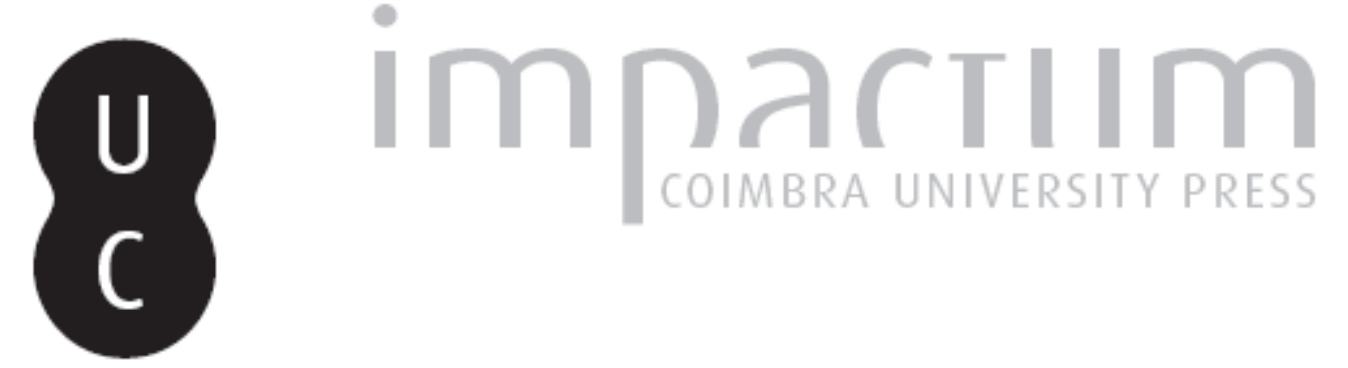

\title{
[Recensão a] PINTO, Rui Pedro - Prémios do espírito - Um Estudo sobre Prémios Literários do Secretariado de Propaganda Nacional do Estado Novo
}
Autor(es):
Neto, Sérgio

Publicado por: Imprensa da Universidade de Coimbra

URL

persistente:

URI:http://hdl.handle.net/10316.2/36454

DOI:

DOI:http://dx.doi.org/10.14195/1647-8622_10_25

Accessed : $\quad$ 26-Apr-2023 14:35:43

A navegação consulta e descarregamento dos títulos inseridos nas Bibliotecas Digitais UC Digitalis, UC Pombalina e UC Impactum, pressupõem a aceitação plena e sem reservas dos Termos e Condições de Uso destas Bibliotecas Digitais, disponíveis em https://digitalis.uc.pt/pt-pt/termos.

Conforme exposto nos referidos Termos e Condições de Uso, o descarregamento de títulos de acesso restrito requer uma licença válida de autorização devendo o utilizador aceder ao(s) documento(s) a partir de um endereço de IP da instituição detentora da supramencionada licença.

Ao utilizador é apenas permitido o descarregamento para uso pessoal, pelo que o emprego do(s) título(s) descarregado(s) para outro fim, designadamente comercial, carece de autorização do respetivo autor ou editor da obra.

Na medida em que todas as obras da UC Digitalis se encontram protegidas pelo Código do Direito de Autor e Direitos Conexos e demais legislação aplicável, toda a cópia, parcial ou total, deste documento, nos casos em que é legalmente admitida, deverá conter ou fazer-se acompanhar por este aviso.

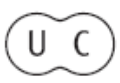




\section{crises do século}

\section{ESTUD OSD OSÉCULO}

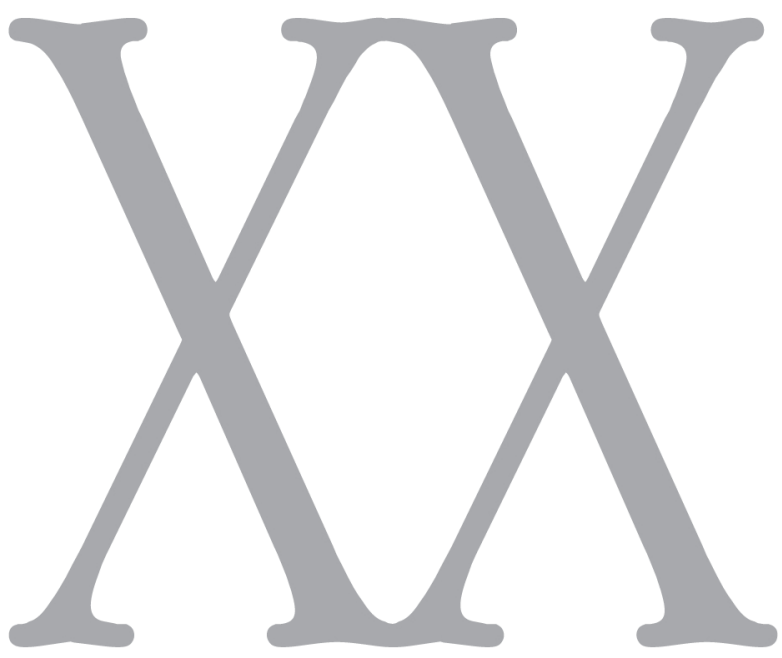

número $10 \cdot 2010$

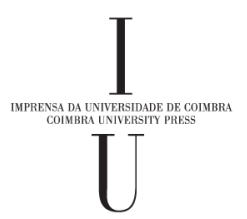


PINTO, Rui Pedro - Prémios do espirito - Um Estudo sobre Prémios Literários do Secretariado de Propaganda Nacional do Estado Novo. Lisboa: Imprensa de Ciências Sociais, 2008. 189 p.

1. Sociólogo e docente da Escola Superior de Educação do Instituto Politécnico do Porto, Rui Pedro Pinto apresenta, em Prémios do Espirito, uma visão lúcida dos mecanismos dos «Prémios Literários» promovidos pelo Secretariado da Propaganda Nacional (SPN). Correspondendo, no essencial, à sua dissertaçáo de mestrado em Ciências Sociais, o livro aqui passado em revista, na medida em que procura ser inovador na temática abordada, assim como na utensilagem teórico-conceptual, recebeu rasgados elogios de historiadores consagrados. $\mathrm{Na}$ verdade, o principal mérito desta obra consiste na objectiva e detalhada viagem aos bastidores da propaganda do Estado Novo, aliando a clareza da exposição à diversidade das fontes consultadas. Nunca perdendo de vista a complexa personalidade do primeiro director do SPN, António Ferro - que oscilou entre vanguardismo e tradicionalismo, num composto ideológico nem sempre harmónico -, Prémios do Espirito examina as ainda mais complexas relaçóes entre escritores, literatura e regime. Trata-se, pois, de um estudo a todos os títulos relevante, que importa analisar pormenorizadamente.

2. A estrutura da obra compreende duas partes, a primeira das quais cindida em três capítulos, e a segunda abarcando apenas um único. Sendo intenção do autor realizar «uma reflexão sobre as linhas da (tomada de) posição do campo de poder perante o campo cultural» (p. 11), o primeiro capítulo da primeira parte de Prémios do Espirito (pp. 15-42) começa exactamente por caracterizar os vectores ideológicos do Estado Novo: ponto de convergência do "catolicismo integrista», do conservadorismo republicano, do integralismo lusitano e do "nacionalismo autoritário» de raiz sidonista e fascista, o Estado Novo surge como uma plataforma ou polifonia das diversas famílias da direita portuguesa. Ao mesmo tempo, Rui Pedro Pinto destaca os pontos cardeais da visáo do mundo do regime de Salazar, nomeadamente o «viver habitualmente», a banalização da pobreza e o "autoritarismo conservador» de feição paternalista, sem esquecer uma certa mobilização das massas que se pretendia, por isso mesmo, desmobilizante - através de uma "estetização da política» (p. 26), da qual os «Prémios Literários» do SPN foram importante veículo. Depois, o autor aborda, ainda que de forma lateral, o papel da Fundação Nacional para a Alegria no Trabalho (FNAT), da Mocidade Portuguesa (MP), da Legiáo Portuguesa (LP), das corporaçóes e do sistema de ensino, enquanto organismos complementares do SPN na tarefa da "monitorização e inculcação ideológica» da visão oficial estadonovista. Algumas páginas são dedicadas ao aparelho censório.

Por seu lado, o segundo capítulo, «A Cruzada do SPN» (pp. 43-68), introduz o ambiente que rodeou a institucionalização daquele organismo e a atribuição dos primeiros "Prémios Literários", a partir de 1934. Criado em Setembro de 1933, na dependência directa da Presidência do Conselho de Ministros, o SPN teve em António Ferro, jornalista, antigo editor da revista Orpheu e apologista de uma consistente "política do espírito", o seu primeiro director. Amalgamando o ideário conservador/tradicionalista do Estado Novo e o passado modernista de Ferro, o SPN desenvolveu uma série de iniciativas destinadas a convencer o público nacional 
e estrangeiro da obra de ressurgimento encetada pelo regime. Foi assim que, através de uma «representação maniqueísta da realidade» (p. 46), se impulsionaram, entre muitas outras actividades: exposiçôes diversas; concursos, como o da «Aldeia mais Portuguesa de Portugal» ou o «Concurso das Montras» ou aqueloutro das «Estaçôes Floridas»; e se criou o grupo de bailado Verde Gaio, reflectindo o fascínio de Ferro pelos Ballets Russes, de Serguei Diaguilev. A conclusão a extrair é que, partindo em busca da "genuidade cultural do arquétipo de ser português», através de um "nacionalismo ruralista», apto a espelhar uma «imagem mítica do povo», a propaganda foi «mais persuasiva do que impositiva» (pp. 57-59) - pelo menos até à primeira grande crise do regime, ocorrida nos finais da Segunda Guerra Mundial.

O terceiro capítulo trata directamente os «Prémios Literários», cuja lista incluía: o «Prémio Camóes», consagrando a melhor obra estrangeira sobre Portugal; o «Prémio António Enes» (doutrina ou polémica); o «Prémio Alexandre Herculano» (História); o "Prémio Anselmo de Andrade» (ensaio de doutrina política ou económica), atribuído a partir de 1945; o "Prémio Ramalho Ortigão» (ensaio); o "Prémio Antero de Quental» (poesia); o "Prémio Eça de Queirós» (romance); o «Prémio Maria Amália Vaz de Carvalho» (literatura infantil); o "Prémio Afonso de Bragança» (jornalismo/reportagem); e o "Prémio Gil Vicente» (teatro). Neste particular, o autor discute a contradição inerente aos "Prémios Literários», ou seja, o facto de "a boa literatura", aquela a premiar, encontrar-se sujeita a um «código ideológico no julgamento dos autores e obras que se sobrepunha a exigências de expressão estética» (p. 78). Por outras palavras, o regime, mais do que promover o surgimento de novos valores literários, acabou por tentar coarctar os já existentes, náo sendo de estranhar que boa parte dos autores premiados pertencesse a um círculo fechado de personalidades próximas das coordenadas do Estado Novo. De resto, também não foi caso único os concorrentes vencedores integrarem, nos anos seguintes, o júri desse mesmo prémio ou de outro, facto que confirma as dificuldades na atracção escritores de outros quadrantes, como os presencistas ou os neo-realistas. Tudo isto vem abonar a favor da tese defendida pelo autor, segundo a qual os «Prémios Literários» não conseguiram atingir o fim delineado pelo SPN, pois muitos literatos continuaram a encarar a arte como forma de intervenção social e não veículo da ideologia oficial do regime.

Finalmente, na segunda parte, Rui Pedro Pinto estuda um prémio literário concreto, o "Prémio Camóes», o qual, como se disse, deveria galardoar a melhor obra estrangeira sobre Portugal. Tratava-se, sem dúvida, do prémio mais importante, uma vez que, na sua procura de consenso interno e reconhecimento externo, o Estado Novo ansiava por uma legitimação, aparentemente imparcial, vinda de autores estrangeiros. Com efeito, enquanto os demais prémios distinguiam obras não excessivamente apologéticas do regime, o "Prémio Camóes» assumiu «explicitamente a defesa dos conteúdos ideológicos» salazaristas (p. 118). Um dos seus laureados, o britânico John Gibbons, no famoso I Gathered no Moss («Prémio Camóes» de 1940), buscando uma "correcção da percepção estrangeira sobre Portugal», oferecia aos leitores, na realidade, "um compêndio ideológico do Estado Novo» (p. 116). Para além da crítica à oficialmente estigmatizada Primeira República, Gibbons definia o Presidente do Conselho como o «educador moral» das gentes portuguesas, não se 
eximindo de tecer elogios àquele ruralismo igualmente enaltecido pelo SPN. No fundo, trilhava o mesmo caminho de todos aqueles intelectuais e activistas de direita, como Charles Maurras ou Jacques Ploncard d'Assac, que muito exaltaram o carácter do Estado Novo.

3. Sem ter dissecado todos os géneros dos «Prémios Literários» - até porque já existem artigos versando o "Prémio Antero de Quental»(poesia), o "Prémio Eça de Queirós» (romance) e o "Prémio Gil Vicente» (teatro) - Rui Pedro Pinto oferece-nos um relato fundamentado e completo dos primeiros anos de vida SPN. Captando o espírito da "política do espírito", passe a expressão, o livro deixa adivinhar que o Secretariado Nacional de Informação, Turismo e Cultura (SNI) que sucedeu ao SPN, em 1944, agregando a si os serviços de censura - ostentaria uma face menos criativa e cada vez mais repressiva. Sinais dos tempos.

Sérgio Neto

CEIS20

RIBEIRO, Maria Manuela Tavares (Coord.) - Imaginar a Europa. Coimbra: Almedina/CEIS20, 2009. 153 p. (Estudos Sobre a Europa; 7). ISBN 978-972-40-4046-2.

O número 7 da Colecção Estudos sobre a Europa, a que procederemos uma sucinta análise, escrito para o meio académico apresenta-se também com utilidade para os leitores portugueses que, na sua generalidade, se mostram mal informados sobre as questóes europeias.
Esta obra - Imaginar a Europa - verdadeira síntese que aborda, pensa e reflecte sobre projectos de ordem política, religiosa, económica, social, cultural, como bem sublinha Maria Manuela Tavares Ribeiro na nota introdutória, «é também reflectir sobre o seu destino, o seu posicionamento estratégico, sobre o seu papel no Mundo, sobre um futuro em perspectiva». O estudo proposto é, na linha do publicado na Colecção, extremamente rigoroso e completo.

Parece-nos de todo oportuno perscrutar os seis artigos de especialistas nacionais e estrangeiros que constituem a obra em análise.

Georges Contogeorgis traz à liça o projecto político europeu. Defende que este deve ter como base três ordens de factores, a saber: o estatuto institucional e a sua dinâmica interna; o discurso que ele projecta sobre o seu futuro ideal e a geopolítica planetária. É da articulação destes que a Europa política continuará a «s'accommoder d'un système politique sans État de nature sympolitéinne».

Complementando este olhar político, Peter Antes introduz a questáo religiosa no espaço europeu e a tónica é posta na conhecida evolução da supremacia do Cristianismo ao pluralismo religioso na Europa. Assim, desde a II Guerra Mundial, a nova presença islâmica conjuntamente com o hinduísmo, o budismo, a religiāo Bahai e outros novos movimentos religiosos mudaram a paisagem religiosa europeia e conduziram o pluralismo religioso por caminhos nunca antes percorridos. $\mathrm{O}$ autor defende também que o pluralismo religioso tem uma longa tradição na Europa remontando ao Império Romano antes de Constantino, tendo sido entáo interrompido durante mais de 200 anos como consequência da supremacia do Cristianismo até ser reintroduzido no período pós Segunda Guerra Mundial. 